\title{
A DECISION SUPPORT TOOL ON DERELICT BUILDINGS FOR URBAN REGENERATION
}

\author{
I. Blečić ${ }^{1 *}$, A. Cecchini ${ }^{2}$, M. Minchilli ${ }^{2}$, L.F. Tedeschi ${ }^{2}$, G.A. Trunfio ${ }^{2}$ \\ ${ }^{1}$ Dept. of Civil \& Environmental Engineering and Architecture, University of Cagliari, \\ Via Santa Croce 67, 09126 Cagliari, Italy - ivanblecic@unica.it \\ ${ }^{2}$ Dept. of Architecture, Design and Urban Planning, University of Sassari, \\ Piazza Duomo 6, 07041 Alghero, Italy - (cecchini,minchilli,lftedeschi,trunfio)@uniss.it
}

KEY WORDS: derelict properties, urban regeneration, decision support system, multi-criteria evaluation, walkability, evolutionary search

\begin{abstract}
:
We present a decision suppport tool for the comparison and selection of projects of integrated renovation of derelict buildings and areas for the purpose of urban regeneration. Each project is defined as a subset of derelict properties to renovate together with their respective designated use, and is scored by the decision support tool on two criteria: expected effort and estimated effectiveness in terms of improved urban capabilities in the urban area of interest. The expected effort is estimated as a global transformation cost, factoring in legal and management overhead costs as well as possible economies of scale. The effectiveness in evaluated in terms of extension of urban capabilities centred on walkable distances. We have implemented a bi-objective evolutionary search algorithm to address the computational complexity of the problem of search for efficient (non-dominated) projects over the two criteria. For the purpose of illustration, we present an example case-study application on the historical core of the city of Sassari, Italy
\end{abstract}

\section{INTRODUCTION}

Derelict buildings and areas are the most visible sign of urban decay. While the process of decay of an urban area may be largely rooted in external forces (demographic, economic, social), derelict properties are frequently dynamically entangled with the process of decay due to the negative externalities such derelict properties exert on the perceived quality, attractiveness and ultimately on the real-estate values of the surrounding urban area (e.g. "broken window" effect (Kelling and Wilson, 1982)). One hence often observes a positive-feedback relationship between the overall decay of an urban area and the derelict properties therein, at once both an effect and a cause of the downward spiral of decay.

However, and precisely because of such dynamic entanglements, derelict properties may offer opportunities to invert the processes of decay and be part of a strategy of urban regeneration. So, a renovation and reuse of derelict properties can spur a "renovation atmosphere" in the neighbourhood, and eventually invert the trend and foster an upward spiral. The magnitude of the positive effect of such processes lingers on two factors: the concurrency and the systemic effect of properties being renovated. So, the effectiveness is greater when the renovation is concurrent over many properties, and the properties involved have the potential to exert greater positive externalities and spillover effects (given their position, attractiveness, and designated use) on the surrounding area.

Often such concurrency, and especially selective renovation of properties for greater systemic effect, do not and cannot happen spontaneously: a low rent gap offering small and uncertain incentives to individual property owners, legal constraints, multiple and fragmented ownerships, and other factors may hamper

${ }^{*}$ Corresponding author spontaneous processes of renovation which may, on the aggregate, prove to be collectively beneficial. Some intervention by the public hand is sometimes the only effective way to address this special case of market failure and to solve the problem of collective action.

With that goal in mind, we have developed a decision support tool to assist public policy makers select and prioritise projects of integrated building renovation. The tool suggests a set of possible projects by estimating their expected cost effort on one hand, and on the other by simulating their beneficial systemic effects in terms of improved urban capabilities in the neighbourhood.

In the next section we briefly mention some previous applications in this domain reported in literature, and, with respect to these, highlight the specificities of our approach. Then, in the following section we present the evaluation model with its three main modules: (1) the estimation of transformation costs of projects; (2) the evaluation of effects on urban capabilities; and (3) the project selection procedure which is stated as a portfolio selection problem through combinatorial optimisation. For the purpose of illustration, in the subsequent section we present an example application on the historic core of the city of Sassari, Italy. In the final section we offer some conclusive remarks and suggest lines for future developments.

\section{RELATED WORK}

Similar applications in this domain have been treated in literature, with a concurrent development of a number of evaluation models and tools to address the problem of selection of buildings to renovate, restore, or redevelop for the purpose of urban regeneration. Several authors report methods of portfolio selection with multicriteria evaluation modelling using discrete linear programming (Nesticò et al., 2018), analytic network process (Wang and Zeng, 2010, Wang et al., 2013), and fuzzy-logic approaches (Jankowski 
et al., 2014, Zhou and Zhou, 2015). Somewhat similar to our approach, some work has been done in employing evolutionary search algorithms (Morio et al., 2013, Jankowski et al., 2014) for the purpose of portfolio comparison and selection in this domain.

With respect to these applications, the first specificity of our tool resides in the choice of urban capabilities centred on walkability as the main informative focus for the evaluation of effects of building renovation. That required a specific evaluation submodel (Capability-Wise Walkability Score, CAWS) to be integrated into our tool, with dedicated assessment of not only walking distances, but also of the qualities of the pedestrian routes relevant for their walkability. This opens up the possibility to also account in our tool for other types of interventions and public works not directly related to individual buildings, but whose goal is to improve the quality of public spaces in the urban area under examination.

The second distinctive specificity of our approach resides in its flexible granularity combined with scalability for a large number of available building for potential renovation. In fact, the evolutionary search algorithm we employ for the selection of projects as a computational heuristics allows the comparison of projects comprising buildings out or an initial set of thousands of potential properties, thus permitting evaluations on larger spatial scales. Such combination of granularity-cum-scalability for large number of entities to include in projects (portfolios) has not, to our knowledge, yet been obtained in applications in this specific domain reported in literature.

\section{EVALUATION MODEL}

The evaluation model we present here was designed to compare projects of integrated building renovation. A project is defined as a portfolio of buildings (chosen among the entire set of available derelict properties), together with their designated use after the renovation (e.g. commercial, services, recreation facility, green area, residential) for each building in the portfolio. Hence, given the set $B$ of available properties and the set $\Delta$ of possible designated uses, a project is defined as:

$$
P=\left\{\left\langle b_{1}, \delta_{1}\right\rangle, \ldots\left\langle b_{k}, \delta_{k}\right\rangle\right\}
$$

where $b_{i} \in B$ is a building, and $\delta_{i} \in \Delta$ is the designated use for that building after the renovation.

The comparison among projects is performed against two criteria: (1) the expected effort required for the renovation of buildings into their designated uses; and (2) the effect on overall urban capabilities due to the project.

Hence, to suggest urban regeneration strategies to policy makers, our decision support tool is set with the task to search for the set of non-dominated projects with respect to the two criteria: expected effort (the lower the better), and the effectiveness in terms extension of urban capabilities (the greater the better).

As described in the following sections 3.1 and 3.2, both criteria can be expressed as a function of a project $P$. Therefore, according to Eq. (1), the search space contains a finite number of possible solutions and the problem in question can be viewed as that of a combinatorial optimisation. Since the number of possible projects grows exponentially with the number of available buildings (with $n$ available buildings and $d$ possible destinations, the number of projects is $\left.(d+1)^{n}\right)$, solving the problem by an exhaustive search would not be feasible in general.
Hence, to address the bi-objective optimisation we implement a heuristic search based on a well-known evolutionary algorithm (Coello Coello et al., 2010).

In the following subsections we present in more detail the model for the evaluation of the two criteria and the bi-objective search algorithm.

\subsection{Expected effort}

The expected effort - the first criterion of comparison among projects - is an estimation of the global transformation costs of a project. Our estimations include direct costs of construction for each building in the portfolio, but also attempt to factor in costs related to possible overheads due to legal and ownership issues, as well as potential economies of scale related to concurrent construction works on multiple buildings (due to possible logistics, infrastructure works, project management, procurement and contracting savings) (Ariffin et al., 2016).

To evaluate the global transformation cost of a project, the model uses a series of $m$ quantitative and qualitative attributes $\left(a_{i, 1}, \ldots, a_{i, m}\right)$ available in the GIS database, describing the characteristics and conditions of each derelict building $b_{i}$.

Generally, the global transformation cost of a project $P$ is defined as:

$$
C=s \sum_{i=1}^{n} f\left(b_{i}, \delta_{i}\right)
$$

where:

- $f\left(b_{i}, \delta_{i}\right)$ is the function yielding the estimated cost of transformation of the building $i$ into its designated use $\delta_{i}$. For this estimate, the function uses several building attributes (such as structural condition and state of conservation, number of storeys, conservation constraints) to compute the unit cost of transformation; this unit cost is then corrected by factors accounting for transformation complexity related to possible legal overheads and planning constraints, using building attributes related to ownership (public vs. private), ownership fragmentation, and planning rules (it is important to point out that the transformation costs may vary from one to another type of designated use); finally this corrected unit cost is multiplied by the size parameter of the building (usually square metre);

- $s$ is the economy of scale parameter, factoring in the scale of the project.

To apply the decision support tool on a particular city, the parameters and workings of this general modelling need to be adapted to the local context, taking into account specific features of the local construction market, legal and planning framework, contracting procedures, and project management practices. In the next section we present one example parametrisation of the model adapted for the city of Sassari in Italy.

\subsection{Effects on urban capabilities}

The effect of each project - the second criterion of comparison - is evaluated in terms of extension of urban capabilities (Blečić et al., 2013) centred on walkable distances. For this criterion we employ the Capability-Wise Walkability Score (CAWS) (Blečić 
et al., 2015). CAWS is a score assigned to each point in space, aggregating the information on: (1) the number and variety of available destinations ("urban opportunities") reachable by foot, (2) their distances; and (3) the quality of pedestrian routes, i.e. walkability towards those destinations. "Urban opportunities" should in principle include all points-of-interest, commercial activities, services, educational facilities, parks and green areas, indoor and outdoor recreational facilities and any other kind of businesses activity and urban amenities open to the general public, providing service and option for visiting and doing things, and hence extending the capabilities of inhabitants and city users.

Therefore, rather than evaluating how a place is walkable in itself, CAWS reflects how and where to one can walk from that place, in other words, what is the walkability the place is endowed with. (For details on CAWS methodology and evaluation modelling see (Blečić et al., 2015))

The CAWS model is based on the assumption that a resident living at a point in space has the capability to walk to available destinations a certain amount of times, and can from that derive some benefit $\beta$ defined by the following constant elasticity of substitution (CES) function:

$$
\beta(\mathbf{x})=\left(\sum_{i=1}^{n} x_{i}^{\rho}\right)^{\frac{1}{\rho}}
$$

where $n$ is the number of available destinations, $x_{i}$ is the number of times the resident visits the $i$-th destination and $1 /(1-\rho)$ is the elasticity of substitution among destinations.

The constraint imposed upon on the resident is:

$$
\sum_{i=1}^{n} c_{i} x_{i} \leq \mu
$$

where $c_{i}$ is the cost the resident foregoes to reach the destination $i$, and $\mu$ is the available budget (to which we assign a conventional constant value).

So, the rationale for this modelling is that the number of times a resident walks to all available destinations is constrained by the cost of reaching them, given a finite budget assigned.

The cost $c_{i}$ in CAWS accounts both for the distance and the quality of pedestrian routes (i.e. walkability). Specifically, the distance along the street network is corrected for the walkability of the pedestrian route, by taking into account attributes of the street network relevant for shaping the quality of the pedestrian accessibility, such as physical features, urban design and perceived quality of public space, traffic and road conditions, land-use patterns, presence (or absence) of variety of urban activities, building accessibility, degree of integration with the surroundings, safety and any other feature important to pedestrians' perception of walkability (again, for more details on cost modelling for walkability, see (Blečić et al., 2015))

Finally, the walkability score $w$ attributed to a point in space is defined as the maximum benefit which, under the assumption of the above modelling model, may be yielded by a person residing at that specific point. In other words, for each node in the graph the walkability score is:

$$
w=\max \beta(\mathbf{x})
$$

Under the constraint given by Eq. (4), this optimisation problem is solved by the following values of $x_{i}$ :

$$
x_{i}=\frac{c_{i}^{\frac{1}{\rho-1}} \mu}{\sum_{j=1}^{n} c_{j}^{\frac{\rho}{\rho-1}}}
$$

\subsection{Evolutionary bi-objective search}

Being able to evaluate each project on the two criteria (expected effort and effects on urban capabilities) leaves us with the problem of bi-objective selection of efficient (non-dominated) projects. An exhaustive search over all constructible projects can be computationally challenging, since, as we said, the number of possible projects grows exponentially with the number of available buildings in the set $\Delta$. Therefore, for this specific problem we have adapted and implemented into the tool the wellknown multi-objective Genetic Algorithm (GA) NSGA-II (Deb et al., 2002, Coello et al., 2002), which has been extensively investigated and successfully tested (Deb et al., 2002, Jensen, 2003, Blecic et al., 2007, Blecic et al., 2017, Arca et al., 2015).

In our algorithm, the population to be evolved is initialised with randomly generated projects (each defined as the subset of buildings and their respective designated use, see Eq. (1)).

The GA is then used to evolve this population of $n_{p}$ candidate projects. Each project $\mathcal{P}$ is encoded as an array of integers $\mathbf{b}$, whose generic component $b_{i}$ represents the $i d$ of a building. The initial population is composed of $n_{p}$ individuals, each with a different number of buildings within a prefixed maximum.

After the population has been initialised, the individuals are made to evolve according to the standard NSGA-II algorithm through a predefined number of generations, in order to obtain a suitable set of non-dominated design outlines. At each generation, two individuals can be selected and recombined to form offspring individuals, and the latter can then be mutated to compete with the previous population. In particular, since the population can be composed of individuals with different lengths, the usual simple crossover operators for combining individuals with the same length would not be suitable in our situation. Therefore, following the approach proposed in (Goldberg et al., 1989), we apply, with probability $\epsilon_{c}$, a crossover operator based on the "cut and splice' approach, in which cutting points are chosen separately for the two selected parents $\mathcal{P}_{i}$ and $\mathcal{P}_{j}$. Moreover, in order to avoid the competing convention problem (i.e. two chromosomes representing the same candidate FT) (Hancock, 1992), we sort the elements of each individual before applying the crossover operator.

As for mutations, given the candidate solution $\mathcal{P}^{*}$, we operate as follows:

- removal: each building $b \in \mathcal{T}^{*}$ can be removed with probability $\epsilon_{r}$;

- insertion: a new building can be added to the individual $\mathcal{P}^{*}$ with probability $\epsilon_{a}$;

- replacement: with probability $\epsilon_{e}$, each $b \in \mathcal{P}^{*}$ can be replaced by a new randomly chosen building; 


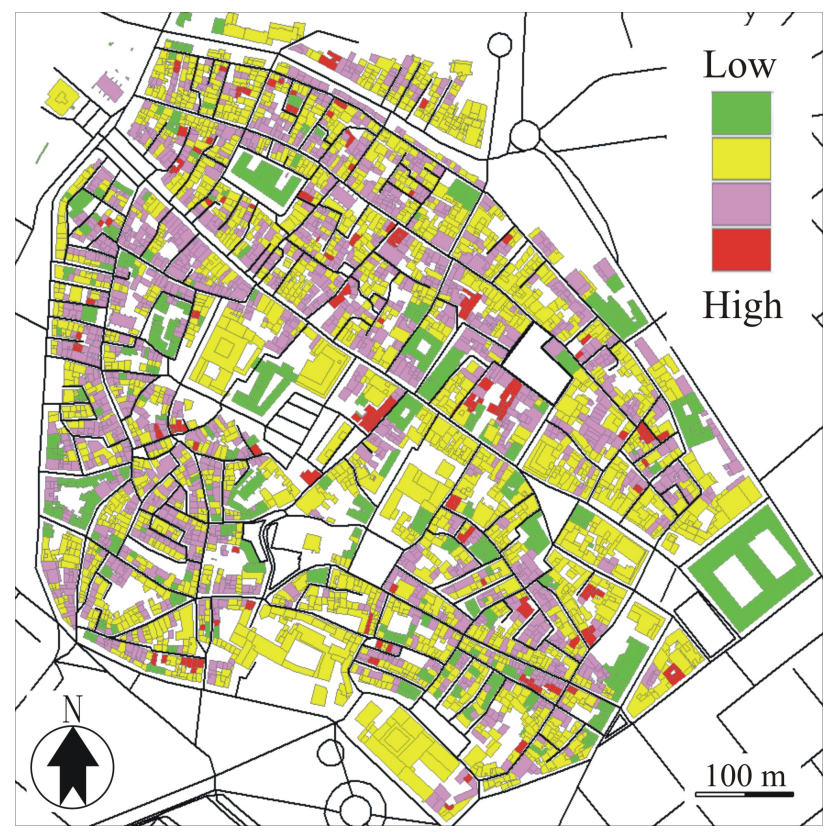

Figure 1. Map representing the state of the buildings in terms of transformation cost, from low to high.

Each generation involves the creation of a hierarchy of Paretoefficient frontiers, which are subsets of non-dominated individuals. The frontiers are created using the Goldberg's non-dominated sorting procedure (Goldberg, 1998).

\section{EXAMPLE APPLICATION}

From 40.000 at its peak, in the last three decades the historical core of Sassari has seen a dramatic loss of residents, to the current 9.000, of which about 2.000 are relatively recent immigrants to Italy. The decline was accompanied by the closure of many local businesses and small commercial activities servicing the neighbourhood. All this has left behind a considerable number of abandoned and derelict buildings in variable structural conditions and degree of conservation.

For the application of the tool on the historic core of Sassari, we have carried out an extensive survey and mapped in a GIS all the derelict buildings, together with their attributes relevant for the evaluation. In Fig. 1 we present a map of the urban area in question with an aggregate information on the state of the buildings and their average estimated transformation costs. The data on the physical and structural conditions of properties were obtained through a direct survey of buildings, while their legal status (ownership, planning destination and conservation constraints) was provided by the Municipality of Sassari. In the following subsection we present more in detail the procedure developed for the estimation of transformation costs.

\subsection{Evaluating expected effort}

To estimate the expected effort as global transformation cost in Eq. (2) we employ building attributes from the survey. The attributes are divided in:

- a size parameter $S$

- a baseline unit cost $B$
- construction cost modifiers $\left(c_{1}, \ldots, c_{n}\right)$

- cost modifiers for complexity $\left(z_{1}, \ldots, z_{m}\right)$

These attributes are combined to compute the value of the function $f(b, \delta)$ in Eq. (2) in the following manner:

$$
f(b, \delta)=\left(\prod_{i=1}^{n} c_{i}\right)\left(\prod_{i=1}^{m} z_{i}\right) B S
$$

In Table 1 we report the attributes we used to estimate the transformation costs together with their reference values, for this specific application on the city of Sassari.

\begin{tabular}{|c|c|c|c|}
\hline Attribute & Type & Scale/u.m. & Value in Eq. (7) \\
\hline $\begin{array}{l}\text { Gross floor } \\
\text { area }\end{array}$ & $\mathrm{S}$ & $m^{2}$ & area in $m^{2}$ \\
\hline $\begin{array}{l}\text { State of } \\
\text { building }\end{array}$ & B & $\begin{array}{l}\text { qualitative } \\
\text { levels }\end{array}$ & $\begin{array}{l}€ 400-1.400 \text { obtained } \\
\text { from a lookup table } \\
(\text { levels } \times \text { possible uses } \\
(\text { from the set } \Delta) \text { ) }\end{array}$ \\
\hline $\begin{array}{l}\text { External } \\
\text { walls }\end{array}$ & $\mathrm{c}$ & $\begin{array}{l}\text { qualitative } \\
\text { levels }\end{array}$ & $0.8-1.2$ \\
\hline Roof & $\mathrm{c}$ & $\begin{array}{l}\text { qualitative } \\
\text { levels }\end{array}$ & $0.8-1.2$ \\
\hline Ownership & $\mathrm{z}$ & $\begin{array}{l}\text { Public, } \\
\text { Mixed, } \\
\text { Private }\end{array}$ & $0.8,1,1.2$ \\
\hline $\begin{array}{l}\text { Ownership } \\
\text { fragmenta- } \\
\text { tion }\end{array}$ & $\mathrm{Z}$ & $1,2-4,>4$ & $1,1.2,1.4$ \\
\hline $\begin{array}{l}\text { Conservation } \\
\text { constraints }\end{array}$ & $\mathrm{Z}$ & levels & $1-1.4$ \\
\hline $\begin{array}{l}\text { Planning } \\
\text { destination }\end{array}$ & $\mathrm{z}$ & $\begin{array}{l}\text { compatible, } \\
\text { incompati- } \\
\text { ble }\end{array}$ & $1,1.2$ \\
\hline
\end{tabular}

Table 1. Building attributes for the estimation of the transformation cost of buildings

For the factor of economies of scale ( $s$ in Eq. (2)), which is a global project-level parameter, we use the sum of the transformation cost for all the buildings in a project, as a proxy for the scale of the project:

$$
s=k \log _{\sigma} \frac{C}{\gamma}+1
$$

where $\gamma$ is a constant amount designating the cost of a unit transformation with no economies of scale, $\sigma$ is the scaling factor, and $k$ is a parameter indicating the strength of the economies of scale effect. In our application on Sassari, we use $\gamma=€ 100.000$, $\sigma=10$ and $k=-0.1$

\subsection{Evaluating effects on urban capabilities}

For the evaluation of the effects of projects on urban capabilities, we have first built the database of urban opportunities, downloading all the points-of-interest available in Google Places. We have used the Open Street Map data for the street network, enriched with further street attributes relevant for walkability which we have collected through an direct audit. As resulting from the latter, in Fig. 2 we show the unit costs (i.e. walkabilities) that are used for computing the values $c_{i}$ in Eq. 4 . 
In Figure 3 we show the set of destinations and the respective status quo capability-wise walkability scores (CAWS) calculated respectively for points-of-interest representing commercial and retail activities.

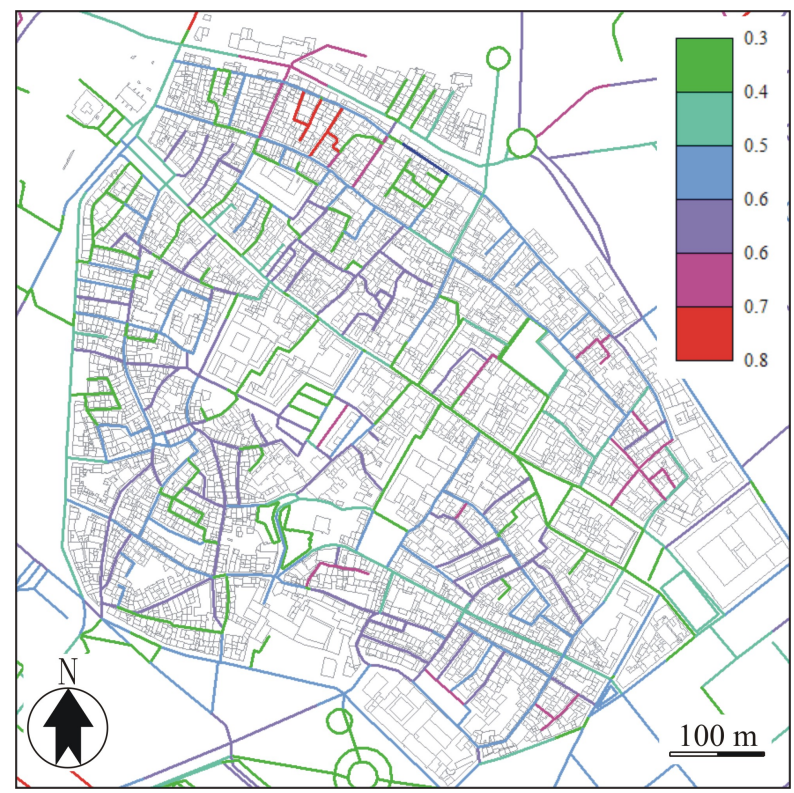

Figure 2. Map representing the unit costs of the street arcs as resulting from data collected through an direct audit.

\subsection{Search for non-dominated projects}

For the bi-objective search on non-dominated project, we have configured the NSGA-II to evolve for 50 generations a population composed of $n_{p}=100$ randomly initialised individuals. Moreover, we carried out many preliminary runs of the optimisation process to determine suitable values for the crossover and mutation probabilities. After such a preliminary investigation, we adopted the following rates: $\epsilon_{c}=1.0, \epsilon_{r}=0.02, \epsilon_{r}=0.01$ and $\epsilon_{e}=0.02$.

We have carried out 25 independent optimisation runs with aim to derive a suitable Pareto approximation set. The quality of the latter was evaluated in terms of hypervolume indicator (higher values of the latter corresponds to better qualities of the Pareto approximation set (Zitzler and Thiele, 1998, Zitzler et al., 2003)). Among the performed runs, we selected the best achieved Pareto approximation set, which is represented in Fig. 4. In the latter, the average increment of CAWS due to a non-dominated project is represented as a function of the cost of that project. As one can observe, the NSGA-II algorithm provided 20 non-dominated projects of different costs.

From here, the user can examine more in detail the features and performances of each project. So, for the purpose of illustration, if among the available efficient projects the user selects the one highlighted in Fig. 4 (corresponding to a cost of $€ 9,312,000$ ) the tool shows (Fig. 5) the 66 buildings that are involved in the project (several buildings are contiguous) together with their suggested uses. Finally, the tool also provides (Fig. 6) an estimation of the effect of that project on the values of CAWS, that is to say, on urban capabilities in the area.

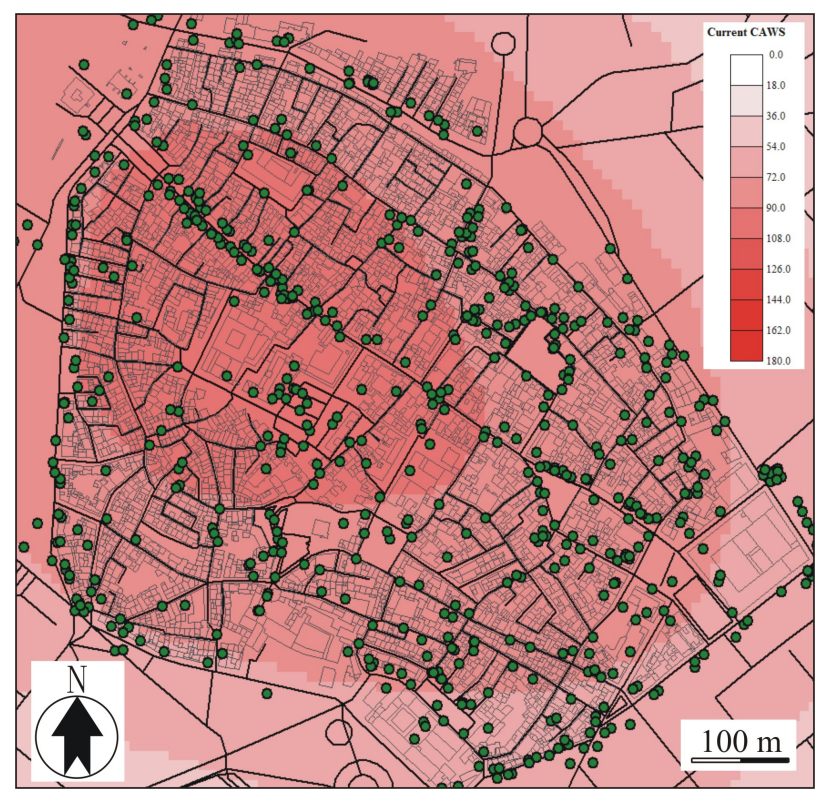

Figure 3. Status quo capability-wise walkability scores (CAWS) for points-of-interest representing commercial and retail activities

\section{CONCLUSIONS AND FUTURE DEVELOPMENTS}

The evaluation and decision support tool we presented in this paper is a preliminary version of a potentially more comprehensive decision support system for guidance in the design of public policies for urban regeneration. Its distinctive feature is to be able to compare projects of simultaneous renovation of multiple properties with respect to their expected global total costs and to the projects' estimated beneficial effects on the local extension of urban capabilities.

According to (Batty et al., 2012), one of the key features of smart cities lies in exploiting data and technologies to improve equity and quality of life for citizens. The proposed approach provides a contribution in such a direction as it actively supports the design of public policies for urban regeneration by explicitly considering the maximisation of urban capabilities as a core factor of urban quality of life.

While it may be argued that the specific methodology we adopted for the evaluation of urban capabilities is not as comprehensive as to capture all the nuances of the concept developed within the capability approach, we hold that the decision support tool still shows promising as an operational tool with the purpose to assist and orient public policy decision makers in that direction. The fact that we throw walkability in the blend when evaluating capabilities further opens up the possibility to also account for other types of interventions and public works not directly related to individual buildings, but whose goal is to improve the quality of public spaces.

Another practically relevant feature of the tool is the purposespecific implementation of a evolutionary search algorithm which allows the comparison of many possible projects, out of a large number or potential properties. Besides granting wide scalability for applications over larger urban areas, this can prove to be of a great heuristic value, offering a series of efficient blueprints for the design and further more detailed development of the most promising projects. 


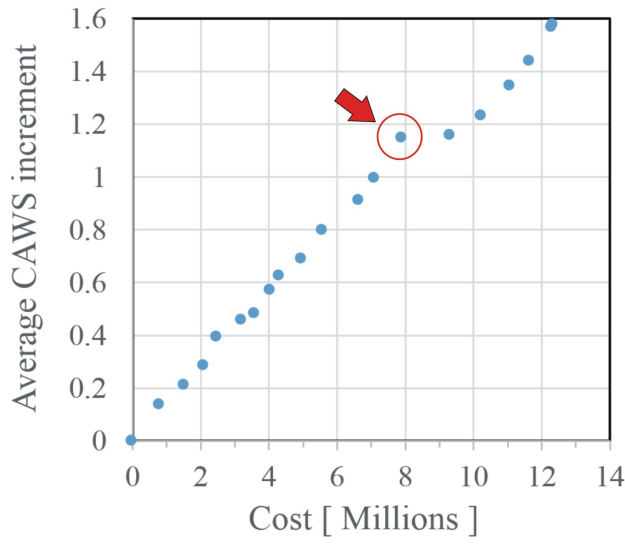

Figure 4. The estimated Pareto front. The selected solution is highlighted in the graph and the map on Figure 5 shows the corresponding buildings object of transformation.

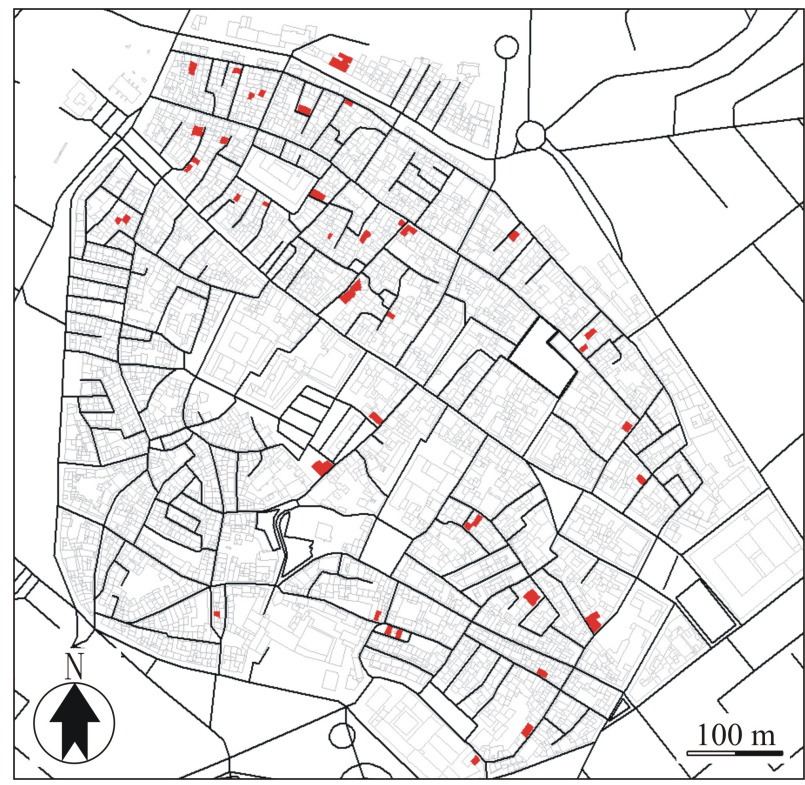

Figure 5. The buildings object of transformation according to the solution highlighted in Figure 4.

The level of detail of analyses and possible granularity of projects though come at a cost. We must emphasise again, as we have shown in our example application on the historic core of the city of Sassari, that the deployment of an instance of the tool for a specific city or urban area requires that features and parameters be adapted to the local context, due to specific legal, contracting and planning aspects and constraints, and due to the conditions of local construction market. This can exact a considerable effort, and require expertise and use of empirical knowledge, especially of the local real-estate and construction market. Also, to properly account for the quality of walkability, a detailed street survey must be undertaken, following a specific audit protocol, which again may prove expensive and time consuming, especially for larger urban areas.

On the side of further refinements and developments of the tool, it would certainly be necessary to include modules for estimating potential direct and indirect financial revenues, so as to also obtain a more comprehensive cost-revenue analysis of the projects. This is a task we plan to undertake in the future developments of

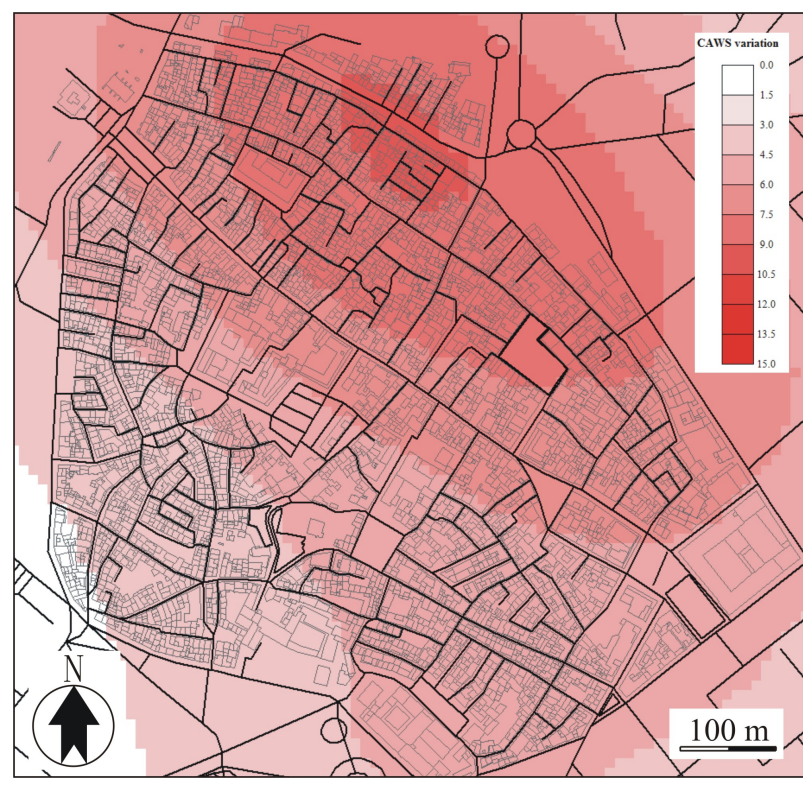

Figure 6. Effect in terms of variation of CAWS due to the transformations hypothesised in Figure 5.

the tool.

Although the general functioning and the results from this first experimental application of the tool seem promising to us, we acknowledge that further experiments and a more careful validation of the tool will be indispensable for it to ultimately prove it's usefulness, versatility and transferability.

\section{ACKNOWLEDGEMENTS}

This study was supported by the research grant for the project "Healthy Cities and Smart Territories" (2016/17) funded by Fondazione di Sardegna and the Autonomous Region of Sardinia.

\section{REFERENCES}

Arca, B., Ghisu, T. and Trunfio, G. A., 2015. GPU-accelerated multi-objective optimization of fuel treatments for mitigating wildfire hazard. J. Comput. Science 11, pp. 258-268.

Ariffin, S., Sulaiman, S., Mohammad, H., Yaman, S. and Yunus, R., 2016. Factors of economies of scale for construction contractors. In: Proceedings of Int. Congress on Technology, Engineering, and Science, Kuala Lumpur, Malaysia, (2016).

Batty, M., Axhausen, K. W., Giannotti, F., Pozdnoukhov, A., Bazzani, A., Wachowicz, M., Ouzounis, G. and Portugali, Y., 2012. Smart cities of the future. The European Physical Journal Special Topics 214(1), pp. 481-518.

Blecic, I., Cecchini, A. and Trunfio, G. A., 2007. A decision support tool coupling a causal model and a multi-objective genetic algorithm. Applied Intelligence 26(2), pp. 125-137.

Blecic, I., Cecchini, A. and Trunfio, G. A., 2017. Computeraided drafting of urban designs for walkability. In: Computational Science and Its Applications - ICCSA 2017, Lecture Notes in Computer Science, Vol. 10407, Springer International Publishing, pp. 695-709.

Blečić, I., Cecchini, A. B. and Talu, V., 2013. The Capability Approach in Urban Quality of Life and Urban Policies: Towards a Conceptual Framework. Springer Netherlands, Dordrecht, pp. 269-288. 
Blečić, I., Cecchini, A., Congiu, T., Fancello, G. and Trunfio, G. A., 2015. Evaluating walkability: a capability-wise planning and design support system. International Journal of Geographical Information Science 29(8), pp. 1350-1374.

Coello, C. C., Veldhuizen, D. V. and Lamont, G., 2002. Evolutionary Algorithms for Solving Multi-Objective Problems. Kluwer Academic Publishers.

Coello Coello, C. A., Dhaenens, C. and Jourdan, L., 2010. MultiObjective Combinatorial Optimization: Problematic and Context. Springer Berlin Heidelberg, Berlin, Heidelberg, pp. 1-21.

Deb, K., Agrawal, S., Pratap, A. and Meyarivan, T., 2002. A fast and elitist multiobjective genetic algorithm: NSGA-II. IEEE Trans. Evolutionary Computation 6(2), pp. 182-197.

Goldberg, D., 1998. Genetic Algorithms and Evolution Strategy in Engineering and Computer Science: Recent Advances and Industrial Applications. Wiley.

Goldberg, D., Deb, K. and Korb, B., 1989. Messy genetic algorithms: motivation, analysis, and first results. Complex Systems (3), pp. 493-530.

Hancock, P., 1992. Genetic algorithms and permutation problems: a comparison of recombination operators for neural net structure specification. In: International Workshop on Combinations of Genetic Algorithms and Neural Networks, pp. 108-122.

Jankowski, P., Fraley, G. and Pebesma, E., 2014. An exploratory approach to spatial decision support. Computers, Environment and Urban Systems 45, pp. $101-113$.

Jensen, M. T., 2003. Reducing the run-time complexity of multiobjective eas: The NSGA-II and other algorithms. IEEE Trans. Evolutionary Computation 7(5), pp. 503-515.

Kelling, J. Q. and Wilson, G. L., 1982. Broken windows: The police and neighborhood safety. Atlantic Monthly.

Morio, M., Schdler, S. and Finkel, M., 2013. Applying a multicriteria genetic algorithm framework for brownfield reuse optimization: Improving redevelopment options based on stakeholder preferences. Journal of Environmental Management 130, pp. $331-346$.

Nesticò, A., Morano, P. and Sica, F., 2018. A model to support the public administration decisions for the investments selection on historic buildings. Journal of Cultural Heritage.

Wang, H.-J. and Zeng, Z.-T., 2010. A multi-objective decisionmaking process for reuse selection of historic buildings. Expert Systems with Applications 37(2), pp. 1241 - 1249.

Wang, W.-M., Lee, A. H., Peng, L.-P. and Wu, Z.-L., 2013. An integrated decision making model for district revitalization and regeneration project selection. Decision Support Systems 54(2), pp. $1092-1103$.

Zhou, T. and Zhou, Y., 2015. Fuzzy comprehensive evaluation of urban regeneration decision-making based on entropy weight method: Case study of yuzhong peninsula, china. Journal of Intelligent and Fuzzy Systems 29(6), pp. 2661-2668.

Zitzler, E. and Thiele, L., 1998. Multiobjective optimization using evolutionary algorithms. a comparative case study. In: A. Eiben, T. Bck, M. Schoenauer and H.-P. Schwefel (eds), Parallel Problem Solving from Nature - PPSN V, Lecture Notes in Computer Science, Vol. 1498, pp. 292-301.

Zitzler, E., Thiele, L., Laumanns, M., Fonseca, C. M. and da Fonseca, V. G., 2003. Performance assessment of multiobjective optimizers: an analysis and review. IEEE Trans. Evolutionary Computation 7(2), pp. 117-132.
Revised October 2017 